\title{
Pegvisomant and not somatostatin receptor ligands (SRLs) is first-line medical therapy for acromegaly
}

\author{
Aart J van der Lely', Emmanuelle Kuhn², Ammar Muhammad', Eva C Coopmans', \\ Sebastian J Neggers ${ }^{1}$ and Philippe Chanson ${ }^{2,3}$ \\ ${ }^{1}$ Division of Endocrinology and the Rotterdam Pituitary Centre, Department of Medicine, Erasmus University MC, \\ Rotterdam, The Netherlands, ${ }^{2}$ Assistance Publique-Hôpitaux de Paris, Hôpitaux Universitaires Paris-Saclay, Hôpital \\ de Bicêtre, Service d'Endocrinologie et des Maladies de la Reproduction, Centre de Référence des Maladies Rares de \\ I'Hypophyse, Le Kremlin Bicêtre, France, and ${ }^{3}$ Université Paris-Saclay, Univ. Paris-Sud, Inserm, Signalisation \\ Hormonale, Physiopathologie Endocrinienne et Métabolique, Le Kremlin-Bicêtre, France
}

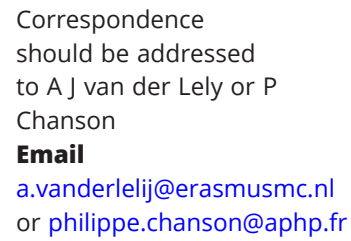

a.vanderlelij@erasmusmc.nl or philippe.chanson@aphp.fr

\section{Abstract}

Current guidelines recommend the use of long-acting somatostatin receptor ligands (SRLs) first when surgery fails to correct GH/IGF-I hypersecretion in patients with acromegaly. In this issue of the journal, a pro- and contra debate will outline which arguments are in favour and which are against positioning pegvisomant (PEGV), a GH receptor antagonist, as the first-line treatment modality of acromegaly. The task of the pros was to promote a paradigm shift towards repositioning PEGV as first-line treatment as PEGV is safe and more effective than the first- and secondgeneration of SRLS. SRLS, when prescribed together with PEGV can still reduce tumour size when necessary, while they decrease the necessary dose of PEGV by around $50 \%$ in the average patient. They conclude that PEGV must move up towards the first-line treatment. For the cons, SRLs remain the first-line medical treatment. Indeed, even if, in recent studies, the remission rate is lower than initially claimed, SRLs are still effective not only for normalizing GH/IGF-I levels in half of the patients but also for inducing tumour shrinkage, improving comorbidities and headaches and reversing excess mortality. They are more convenient for use with their monthly administration and have a remarkable safety profile as demonstrated by the very prolonged experience acquired by more than 30 years of use. Finally, the costeffectiveness of first-generation SRLs is better than that of PEGV. For all these reasons, cons consider that SRLs remain the best first medical treatment in patients requiring medical therapy.

\section{Introduction}

Acromegaly is a rare disease due to excessive growth hormone $(\mathrm{GH})$ secretion by pituitary adenoma in the majority of cases. If not adequately treated, acromegaly is associated with severe comorbidity and premature death (1). Management of acromegaly is now rather consensual (2). The clinical aims of treatment are to relieve symptoms, to reduce the volume of the pituitary tumour, to avoid tumour relapse, and to improve long-term morbidity and mortality (2). If surgical removal of the pituitary
GH-secreting adenoma is usually the first-line therapy, it is able to cure the disease only in microadenomas or small non-invasive macroadenomas. In the other cases, persistent postoperative GH/IGF-I hypersecretion needs to be treated with medical therapy which is now generally preferred to radiation therapy for second-line treatment. The most recent consensus statement recommends firstgeneration long-acting somatostatin receptor ligands (SRLs) as the first-line treatment for persistent disease after
Published by Bioscientifica Ltd. 
surgery or in patients in whom surgery is not a good option (2) taking into account the advantages, disadvantages and costs of the different treatment options. Only if there is preexisting clinically relevant impaired glucose metabolism, or if patients are not controlled on first-generation SRLs or have side effects of first-generation SRLs, patients should be switched to pegvisomant (PEGV) (2).

This is in line with the conservative approach on how to best treat acromegaly that consensus statements tend to have as in the series of reports coming from a series of consensus meetings that started in 1999 (3). The report of the 2007 meeting concluded that the use of SRLs is most appropriate as first-line therapy when there is a low probability of a surgical cure (4).

Leonart et al. recently reported the results of a systematic review of 2059 articles of which they included ten randomized controlled trials in a qualitative analysis and seven in a quantitative analysis to conduct the first network meta-analysis simultaneously, comparing all available drugs used in acromegaly treatment so as to provide more robust evidence in this field (5). The network meta-analysis for the efficacy outcome (number of patients achieving IGF-1 control) showed that, not surprisingly, PEGV and lanreotide Autoge $\mathrm{l}^{\circledR}$ were statistically superior to placebo (5). The probability rank indicated that PEGV and pasireotide have the highest probabilities (33 and 34\%, respectively) of being the best therapeutic option (5).

The same author also reported recently the outcome of a systematic review and meta-analysis of observational longitudinal studies on the effectiveness and safety of PEGV therapy (6). For that analysis, initially 552 papers were retrieved from the databases and 31 articles were included in the qualitative analysis and 14 in the quantitative analysis. The overall rate of patients with disease control of PEGV-treated patients was $61 \%$. When considering patients under PEGV monotherapy, the control rate was $72 \%$. Tumour growth in the PEGVtreated group was estimated in $7.3 \%$ (6). In literature it is recognized that PEGV is superior to other medical treatment modalities but that it has to be reserved for those patients that cannot be adequately controlled by SRL (alone).

Pros will thus try to convince the reader that it is time to place PEGV on top of the list of the first-line medical treatment options, which it deserves after having proved its superior efficacy and good safety profile. Cons will try to convince the same reader that SRLs still remain the first-line medical treatment in these patients thanks to its good efficacy, not only on biochemical targets but also on tumour volume, excellent safety ( $>30$ years of experience) and convenience for use.

\section{Section 1: Pegvisomant and not somatostatin receptor ligands (SRLs) is first-line medical therapy for acromegaly. THE CASE FOR. Aart J. van der Lely, Ammar Muhammad, Eva C. Coopmans, Sebastian J. Neggers (Erasmus University)}

\section{What is the efficacy of pegvisomant?}

The first report on the efficacy of PEGV was based on a 12-week, randomized, double-blind study of three daily doses of PEGV (10, 15 and $20 \mathrm{mg}$ ) and placebo, given subcutaneously, in 112 patients with acromegaly (7). The IGF-I concentrations became normal in up to $89 \%$ of patients in the $20 \mathrm{mg}$ group (7). Also, in a follow-up report on the registration studies of PEGV, the effects of PEGV in 160 patients with acromegaly treated for an average of 425 days were reported (8). Of the 90 patients treated for 12 months or more, 97\% achieved normal serum IGF-I levels (8).

Interestingly, in the reports coming out from the ACROSTUDY data, it is clear that PEGV does not biochemically control virtually all acromegaly patients as was more or less expected. Established in 2004, ACROSTUDY is a global non-interventional safety surveillance study of long-term treatment with PEGV (9, 10). ACROSTUDY is open to all patients with acromegaly who are treated, or planned to be treated, with PEGV in routine clinical practice and contains a growing volume of data on patients with this rare disease. An important part of the current data set has been provided by the German Pegvisomant Observational Study, initiated in January 2004 immediately after PEGV received market authorization in Germany. The German Pegvisomant Observational Study added 254 additional patients to the ACROSTUDY database, which at the time included 310 patients (11).

Trainer et al. reported, in 2009, that after analysing the data of the 792 patients that had been enrolled at that time, $83 \%$ had commenced PEGV prior to recruitment. The mean follow-up was 1.7 years with the mean duration of PEGV therapy of 3.3 years, representing 2625 patient-years of treatment (9). Disappointingly, IGF-I was normalized in $<70 \%$ of patients; furthermore, in $80 \%$ of patients with an elevated IGF-1, the daily dose of PEGV was $20 \mathrm{mg}$ or less. In a report of ACROSTUDY data in 2012, 
van der Lely et al. reported an interim analysis of data captured from 1288 subjects enrolled before a database freeze of end of 2009 (10). A total of 1288 subjects treated with PEGV were included who had been treated for a mean of 3.7 years and followed up in ACROSTUDY for a mean of 2.1 years. Again, it appeared that after 5 years of PEGV treatment, 'only' $63.2 \%$ of subjects had normal IGF-I levels at a mean dose of $18 \mathrm{mg} /$ day (10). It is very likely that the lower-than-expected efficacy of PEGV found in ACROSTUDY could be explained by inadequate dosing by the prescribing physicians or inadequate patient compliance (10). These could be based on lack of knowledge or economic reasons that differ by country. As discussed in the ACROSTUDY reports it is also possible that some patients chose not to increase the dose above $20 \mathrm{mg} /$ day because that would have required two daily injections with the available formulation at that time (10). Also, the original studies by Trainer et al. and van der Lely et al. used a different criterion to assess IGF-1 normalization $(7,8)$. In those reports, if a patient had even a single IGF-I level within the normal reference range at least once during the whole follow-up period, this was classified as normalization of IGF-I. In contrast, in the ACROSTUDY reports, IGF-I normalization was evaluated on a yearly basis $(9,10)$. It is also noteworthy that the efficacy of the PEGV-treated patients is based on data obtained in subjects with acromegaly that were not controlled in their disease activity and biochemical parameters while treated with SRLs. In a report by Neggers et al., the efficacy, defined as the lowest measured IGF-1 level during treatment, was $97.0 \%$ in patients treated with the combination of SRLs and PEGV (12).

Ragonese et al. tried to detect characteristics which improve long-term PEGV effectiveness in 87 acromegaly patients treated with PEGV and seen in seven referral Italian centres (13). PEGV was administered for up to 4 years, at doses up-titrated until IGF-I normalization or up to, but not more than $30 \mathrm{mg} /$ day (13). IGF-I was normalized in $75.9 \%$ of patients after 1 year and in $89.6 \%$ at last visit; disease control was associated with lower baseline GH and IGF-1 levels (13). Apparently, PEGV effectiveness improves when up-titration is appropriate. According to these authors, higher PEGV doses at start and a more rapid up-titration are necessary in patients with obesity and/or high IGF-I levels (13).

This was confirmed by van der Lely et al., who investigated the characteristics of patients who need low or high-dose PEGV to normalize serum IGF-1 levels (14). As of June 2014, ACROSTUDY included data on 2016 patients. All 56 patients on high-dose PEGV (H-group) in this analysis were treated for at least 6 weeks at a dose above $30 \mathrm{mg} /$ day and had two consecutive normal serum IGF-1 concentrations. The 368 patients with two consecutive normal IGF-1 values and who never received a PEGV dose above $10 \mathrm{mg} /$ day (L-group) were included in the analysis as 'low'-dose group. Patients in the H-group turned out to be significantly younger and had a significantly higher BMI. They had more diabetes, sleep apnoea and more hypertension (14). Again, their data indicate that patients who need more PEGV to normalize IGF-1 have more aggressive disease, as they are younger, have higher baseline IGF-1 levels, more hypertension, more sleep apnoea and diabetes, and are more overweight (14). Personalised medical treatment in acromegaly does demand knowledge about the size and extension of the pituitary tumour. For sure, in any patient with a tumour impinging the optic chiasm, surgery and/or SRLs are mandatory interventions. Only when tumour size is not a clinical important issue, PEGV should be considered as first-line treatment because of its superior tract-record on efficacy and better glycaemic control.

In conclusion, even in acromegaly patients in whom (biochemical) disease activity cannot be controlled by SRLs, PEGV can achieve biochemical control in the vast majority of subjects, provided that the appropriate dose has been applied. Therefore, we must conclude that PEGV is superior to SRLs and should be used as the first-line medical treatment, provided that it is safe enough.

\section{Pegvisomant and its effects on acromegaly comorbidities}

Auriemma et al. reported the positive effects of PEGV on cardiac arrhythmias in 13 subjects. Long-term PEGV induced the complete recovery of arrhythmias recorded at baseline in one patient and the improvement of rhythm disorders developed after 6-month therapy in another patient. The results of their study demonstrate that in acromegalic patients resistant to long-term high-dose treatment with SRLs, PEGV treatment induces a significant decrease in , mean, maximum, and minimum heart rate, suggesting that PEGV may play an important role in the improvement of cardiac arrhythmias associated with acromegaly (15).

De Martino et al. reported that long-term treatment with PEGV induced a slight reduction of carotid arteries wall thickness and a significant improvement of brachial arteries vascular function in patients with acromegaly resistant to SRLs (16). Again, these data support the positive effects of PEGV on comorbidities that are disease 
activity dependent. As PEGV has a higher efficacy, it should be favoured over SRLs with their lower efficacy to control disease activity.

Finally, Kuhn et al. reported on PEGVs long-term impact on comorbidities, showing that long-term PEGV therapy not only normalizes IGF-I in a large proportion of patients but also improves cardiac and respiratory comorbidities (17).

\section{Is pegvisomant safe enough to be used as first-line treatment option}

When PEGV would take over the position of SRLs as preferable first-line drug for acromegaly, its safety profile must be sound and solid. The safety of PEGV will be addressed in the paragraphs below where its effect on tumour size will be discussed separate from other side effects.

\section{Pegvisomant and tumour size}

In a recent update on the ACROSTUDY data, Buchfelder et al. also mentioned that of the 2045 patients analysed for pituitary imaging, 1712 patients had at least one local pituitary imaging result reported in follow-up after PEGV start (18). Reports of locally assessed MRIs showed that most patients $(72.2 \%)$ had no change in tumour size relative to the prior scan; $16.8 \%$ had decrease in tumour size, $6.8 \%$ had an increase, and $4.3 \%$ had both an increase and decrease. Changes in tumour size were reported as adverse events for 90 patients (4.3\%) of which 21 (1\%) were considered treatment related (18). Of those listed as treatment related, eight patients $(0.4 \%)$ had been withdrawn from PEGV. As per protocol in ACROSTUDY, any pituitary MRIs showing a significant change were sent for centralized re-assessment (18). Among patients who had an increase as per local reading $(n=119)$, the central reading confirmed an increase in 29 patients; while in 23 patients there was no change in tumour size.

Already in 2005, Besser et al. assessed the literature for relevant data regarding the surgical, medical and radiotherapeutic treatment of acromegaly in order to identify the factors that were predictive of aggressive or treatment-resistant tumour behaviour in acromegaly and undertook an assessment of the rates of failure to control tumour progression with available treatment modalities (19). They reported that young age at diagnosis, large tumour size, high GH secretion and certain histological markers are predictors of future aggressive tumour behaviour (19).
A special group of acromegaly patients are those with an AIP mutation as they respond less to SRLs and are dependent of PEGV for disease control (20).

They also mentioned that SRLs induce a variable degree of tumour shrinkage in acromegaly but up to $2.2 \%$ of SRLtreated tumours continue to grow $(19,21)$. Apparently, treatment-resistant tumour progression occurs in a small minority of patients with acromegaly, regardless of their medical treatment modality (19). Young patients with large tumours or those with high pre-treatment levels of GH in particular warrant close monitoring for continued tumour progression during treatment for acromegaly.

In the Italian ACROSTUDY patients, according to MRI analyses at local centres (data available for 249 patients), a decrease in tumour volume was reported at least once in $13.7 \%$, an increase in $8.8 \%$, and both increase and decrease in $6.4 \%$ in different treatment phases (22). The authors observed that none of the 35 patients under PEGV alone showed significant tumour growth, whereas in one case, MRI documented progressive shrinkage of the adenoma, which was no longer detectable after 6 years of treatment (22). In the same study, among the 27 patients treated with PEGV in combination with SRL, a significant growth $(\geq 25 \%)$ of the residual adenoma tissue occurred in one case. In line with the Bevan and Besser reports $(19,21)$, this patient was characterised by aggressive disease and, when the tumour enlargement was noted, was treated with PEGV $40 \mathrm{mg} /$ day plus lanreotide ATG $120 \mathrm{mg}$ every 4 weeks (22).

It is noteworthy that in patients treated with PEGV, the addition of SRLs still leads to a significant reduction in tumour size as was reported by Franck et al. (23) and Neggers et al. (24). In the report by Neggers et al., they assessed the long-term safety of the combined use of PEGV plus LA-SRLs in a larger group of acromegalic patients over a longer period of time $(n=86)$ (24). In 12 out of 86 patients, no tumour size decrease could be assessed due to empty sella prior to the start of the combined treatment. In $14(19 \%)$ patients out of the remaining 74 patients with an assessable tumour size, the size of the tumour significantly decreased by more than $20 \%$, while in none of the 86 patients tumour size increase was observed (24).

All in all, these data do suggest that PEGV treatment does not cause a clinically significant increase in tumour size in acromegaly patients and should be considered as a safe approach, especially when SRLs still can reduce tumour size in PEGV treated subjects plus the fact that in a small number of LA-SRL treated subjects, an increase in tumour size has been observed as well. 


\section{Elevated transaminases and other safety aspects of PEGV}

In the recent update on ACROSTUDY (18), hepatobiliaryrelated adverse events were reported for $9.8 \%$ of the 2090 patients, of which $4.2 \%$ were considered treatment related. However, PEGV withdrawal for this reason was reported in only nine patients (0.4\%) (18). Of the 1094 patients with normal baseline transaminases (TAs), most continued to have normal TAs values during follow-up (62\%), while in $3 \%$ increases in TAs $>3 \times$ Upper Limit of Normal (ULN) were reported (18). Of the 89 patients entering the study with mildly elevated TAs between $1-3 \times$ ULN, 30 patients (34\%) shifted downwards to normal TAs during follow-up on PEGV treatment, 41 (46\%) remained within their baseline measurement range, while $10 \%$ had TAs $>3 \times$ ULN. Of the seven patients entering the study with TAs of 3-5x ULN, 3 shifted to normal, three shifted to mildly abnormal (between 1 and $3 \times$ ULN) and one patient shifted to $>5 \times$ ULN while on PEGV treatment (18).

When TAs are more frequently assessed, the incidence of transient elevated TAs (TETAs) increases as TETAs were observed in 11 patients (34\%) in a report on the longterm safety of combination therapy (25). Of these 11 subjects with TETAs, six patients (55\%) also suffered from diabetes (25).

In the latest ACROSTUDY report, injection site reactions were reported for 71 patients $(3.4 \%)$ and the majority (65 patients; $3.1 \%$ ) were considered by the investigator to be treatment related (18). Bonert et al. also reported on lipohypertrophy at the site of injection of PEGV (26). Lipohypertrophy regresses in most patients when the PEGV is discontinued (26).

In summary, transient elevated transaminases can be frequently observed during PEGV treatment and especially in the first 1-2 years, but they rarely are clinically relevant, resulting in a need stopping PEGV treatment.

\section{Shifting paradigwwm: Pegvisomant as first-line treatment and if necessary, combined with first- or second-line SRLs}

In the latest consensus statement from 2017 Melmed et al. stated that in partial responders on SLR treatment, one should increase the SRL dose and/or dose frequency (2). If IGF-I levels remain modestly elevated during SRL administration, one should add cabergoline to the SRL. If disease control is not achieved, patients should be switched to the second-generation SRL pasireotide if there is clinically relevant residual tumour on imaging and/or clinical concern of tumour growth (i.e., tumour concern) (2). What this statement supports is that patients with impaired glucose tolerance should be switched to PEGV. Patients with impaired glucose tolerance and tumour concern should be treated with a combination of a firstgeneration SRL and pegvisomant. Those who remain uncontrolled despite second-line medical therapy should be considered for stereotactic radiosurgery (SRS) or surgical intervention. In every day practice, many patients need PEGV as active acromegaly is characterised by an impaired glucose tolerance and also big tumours are often observed as well $(27,28)$.

Therefore, when taken together the data as described above, one must conclude that PEGV is more effective than SRLs in controlling IGF-I. It does not induce increase in tumour size and its safety profile is solid. When proper dosing is applied, the vast majority of subjects will be controlled and only if tumour size brings about potential clinical issues as impingement of the optic chiasm, adding SRLs is advised because of their tumour reducing capacities, even in the presence of PEGV. In Fig. 1, we provide a suggestion on how to treat acromegaly patients, using our proposed prominent position of PEGV as firstline treatment option.

We, therefore, postulate in this position statement as part of the pro-and contra debate in this issue of the journal, that PEGV deserves its logical position as the best candidate for the first-line medical treatment modality for acromegaly patients.

The question is what the role of the second-generation SRL pasireotide should be. To address this, Muhammad et al. assessed the efficacy and safety of pasireotide longacting release (PAS-LAR) alone or in combination with PEGV by switching 61 patients with acromegaly who were well controlled with SRLs and PEGV to PAS-LAR with or without PEGV (29). At baseline, the PEGV dose was reduced by $50 \%$ up to 12 weeks. When IGF-1 remained $\leq 1.2 \times$ ULN after 12 weeks, patients were switched to PAS-LAR $60 \mathrm{mg}$ monotherapy. When IGF-1 was $>1.2 \times$ ULN, patients were switched to PAS-LAR $60 \mathrm{mg}$, and they continued with the $50 \%$ reduced PEGV dose. PAS-LAR was well tolerated, but hyperglycaemia was the most frequent adverse event (29). The frequency of diabetes, however, increased from $32.8 \%$ at baseline to $68.9 \%$ at 24 weeks. Apparently, switching to PAS-LAR, either as monotherapy or in combination with PEGV, can control IGF-1 levels in most patients. PAS-LAR demonstrated a PEGV-sparing effect of $66 \%$ compared with the combination with SRLs. 


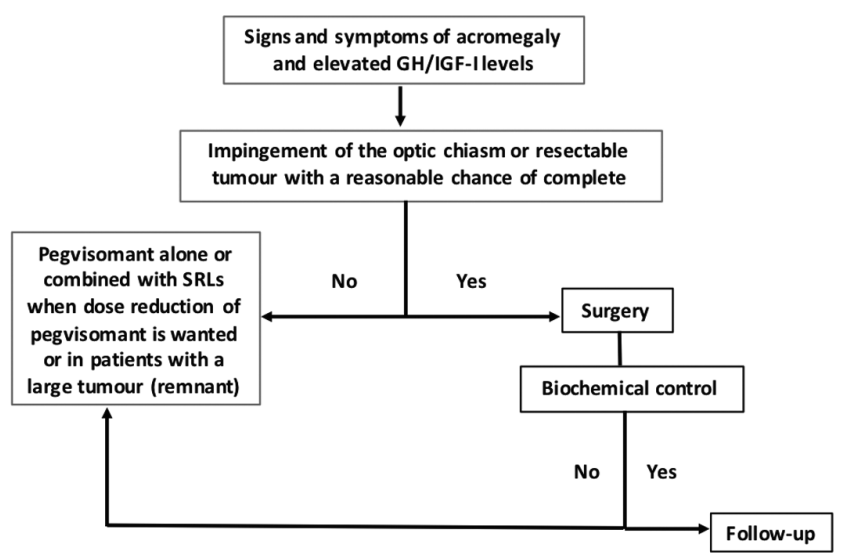

\section{Figure 1}

In patients with active acromegaly and without impingement of the optic chiasm or resectable tumour with a reasonable chance of complete cure, pegvisomant (PEGV) should be used as first-line treatment modality. In patients with large tumours and especially with impingement of the optic chiasm, surgery is warranted. When biochemical control is not achieved by surgery, patients should start PEGV treatment. When dose reduction of PEGV is wanted, cotreatment with long-acting somatostatin receptor ligands (SRLs) can be considered. Also subjects with a large tumour (remnant) can be preferably treated with the combination of PEGV and SRLs. In all patients, proper dosing of PEGV up to the allowed equivalent of $30 \mathrm{mg}$ / day should be applied when biochemical control has not been achieved with a lower dose, regardless whether patients are also treated with SRLs.

Unfortunately, hyperglycaemia was the most important safety issue (29). We think that equal biochemical control when IGF-1 levels are concerned, but with a worsening of glycaemic control in case of PAS-LAR versus an improvement in case of PEGV, should result on favouring PEGV over pasireotide therapy.

In conclusion, the available data on the efficacy and safety of PEGV versus those of the first- and secondgeneration of SRLs clearly show that PEGV is safe and more effective. It does not seem to reduce tumour size, but it also does not increase it, while when necessary, the addition of SRLs to the PEGV treatment can still reduce tumour size in those patients. The first- and secondgeneration SRLs, when prescribed together with PEGV can also reduce the necessary dose of PEGV by around $50 \%$ in the average patient. So, there are no arguments left to keep PEGV as the second-line medical treatment, so it must move up towards the first-line treatment for all acromegaly patients without large tumours impinging the optic chiasm.

\section{Section 2: Pegvisomant and not somatostatin receptor ligands (SRLs) is first line medical therapy for Acromegaly. THE CASE AGAINST. Emmanuelle Kuhn, Philippe Chanson (Hôpitaux Universitaires Paris-Saclay)}

\section{SRLs: oldies but goodies!}

The first SRL, marketed more than 30 years ago, was octreotide (Sandostatin $^{\circledR}$ ) (30) which, at that time was injected subcutaneously (SC), generally by the patient him/herself, at a dose of 100 to $500 \mu \mathrm{g}$ two or three times a day. At that time, it represented a real therapeutic advance (31). The sustained-release version of octreotide, octreotide LAR (Sandostatin ${ }^{\circledR}$ LAR $10-20$ or $30 \mathrm{mg}$ ), which was designed later, is administered intramuscularly, once a month. Treatment is usually started at the median dose and is then adjusted (decreased or increased) according to the GH and IGF-1 concentration (32). Sustainedrelease lanreotide (Somatuline ${ }^{\circledR} \mathrm{LP} 30 \mathrm{mg}$ ) was the first slow-release preparation to be marketed. It was injected intramuscularly every 10 to 14 days (the frequency of injections depending on the impact on the GH and IGF-1 concentration). Lanreotide is now available for deep SC injection every 28 days, at doses of 60,90 and $120 \mathrm{mg}$ (Somatuline ${ }^{\circledR}$ Autoge $^{\circledR}{ }^{60}$, 90 or $120 \mathrm{mg}$ ), and the patient could inject him/herself the drug (33). If necessary, it is possible to increase or decrease the frequency of injections.

\section{SRLs efficacy: Anti-secretory effect}

The large experience accumulated with SRLs and the multiple trials reports have led to the conclusion that control rate of depot SRLs was quite variable from a study to another, without clear explanation about that heterogeneity. A meta-analysis which evaluated if clinical trial design could impact reported biochemical efficacy of SRLs (34), found that the overall mean GH and IGF-1 normalization was 56 and 55\%, respectively, with large confidence intervals. If the treatment duration, the prior SRL therapy and the year of study publication were related to biochemical control, no significant differences in $\mathrm{GH}$ or IGF-1 response rates were observed for multicentre $v s$ single centre, retrospective vs prospective, study drug, preselection for SRL responsiveness, dosing scheme, GH response criterion, or switch study design. The remission rate was found to be lower (around 43-47\%) when studies reported a composite end point taking into account both GH and IGF-1 (34). This lower efficacy rate (compared to 
what was claimed previously) was confirmed by another meta-analysis looking at the effects of SRLs in an unbiased group of treatment-naïve patients: using strict combined cut-off criteria (normal serum IGF-1 levels and serum GH lower than $1 \mu \mathrm{g} / \mathrm{L}$ ), control of GH/IGF-I excess was observed in only $45 \%$ of the patients (35). Fortunately, in some patients, the control rate tends to improve over time as demonstrated in several long-term studies $(36,37,38)$. In rare patients very good responders to SRLs it is possible to lengthen the interval between injections, or even to stop the treatment permanently with no subsequent increase in GH/IGF-I concentrations $(39,40)$.

\section{SRLs efficacy: Tumour shrinkage}

SRLs are associated not only with an anti-secretory effect but also with a reduction in tumour volume in 20 to $70 \%$ of patients $(21,41)$. A meta-analysis concluded that, on average, $53 \%$ of patients treated with octreotide and $66 \%$ of patients treated with octreotide LAR had a tumour shrinkage (42). With octreotide LAR, the overall weighted mean percentage decrease in tumour size was $37.4 \%$, rising to $50.6 \%$ in some series (42). When SRLs are administered as first-line treatment, before surgery, the reduction is more important (43). An overview of published studies evaluating SRLs as first-line therapy showed that a significant (>20-30\%) tumour volume reduction was achieved after 6-24 months of octreotide LAR therapy in $73-85 \%$ of patients, with an overall mean reduction in tumour volume of $35-68 \%$ (44).

In a multicentre prospective study where tumour shrinkage was the primary outcome, $62 \%$ of treatmentnaïve patients had a significant tumour volume reduction $(\geq 20 \%)$ under lanreotide administered at a dose of 120 mg every 4 weeks after 1 year of treatment (45). Generally, the major antitumoral effect is achieved within the first 3 months and slowly progresses thereafter: for example, mean reductions of tumour volume from baseline were $20 \%$ by week $12,25 \%$ by week 24 , and $27 \%$ by week 48 in the latter study (45) (Fig. 2). This effect on tumour volume is a clear advantage over PEGV treatment. Indeed, in the recent report of ACROSTUDY, after PEGV start, local MRI reports showed that most patients $(72.2 \%)$ had no change in tumour while only $16.8 \%$ of patients had a decrease in tumour size (18).

Thus, even if SRLs are able to control GH/IGF-I excess in only half of the patients with acromegaly, they also control tumoral mass in all of them (and even reduce it in more than half of them); importantly this control is protracted which is particularly comfortable for the follow-up of these patients.

\section{SRLs efficacy: Effects on acromegaly comorbidities}

In parallel to normalization of GH/IGF-I levels, SRL treatment is associated with improvement in hard endpoints such as cardiomyopathy $(46,47,48,49,50,51,52$, $53,54)$, obstructive sleep apnoea $(52,54,55,56,57,58$, $59)$, arthropathy $(60,61)$.

It is important to note that this improvement in acromegaly comorbidity under SRL treatment is not limited to the patients who normalized biochemical parameters but also to patients who do not achieve biochemical targets at conventional doses and are considered as partial responders (62). However, even if these objectives are not reached, it is well demonstrated
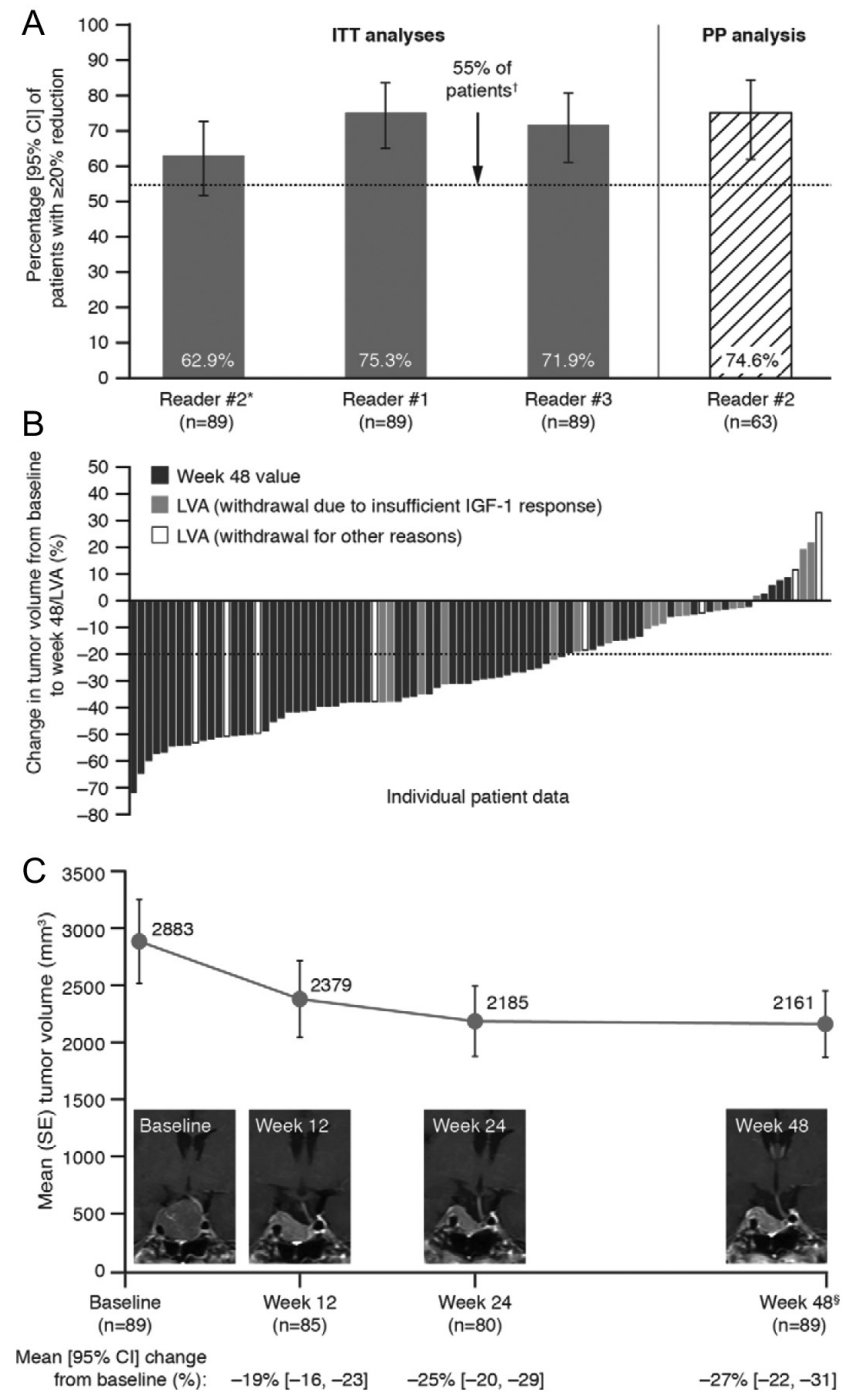

Figure 2

Reductions in tumour volume under SRLs. Reproduced with permission from Caron et al. (45). 
that acromegaly comorbidity may improve thanks to GH/ IGF-I levels reduction $(50,52,54,57,59)$.

There are also few studies analysing the effect of SRLs on headache but they show headache improvement in two-thirds of the patients (63), an effect likely related to the interference with the opioidergic system $(64,65)$, with a rebound headache due to treatment cessation or the development of addiction $(63,66,67)$. Conversely, headache could occur in $1.7 \%$ of patients among during PEGV therapy (68).

\section{SRLs efficacy: Effects on mortality in acromegaly}

Normalization of GH/IGF-I levels, reduction in tumour volume, improvement in comorbidity are important tasks, but this could not be considered as sufficient for the health authorities that may request achievement of harder endpoints such as mortality.

Indeed, several studies described an excess mortality in acromegaly patients compared to the general population, with standard mortality ratios (SMRs) between 1.2 and 3.3 (69). This is related to cardiovascular, cerebrovascular and respiratory diseases, and sometimes malignancies (70). Evidence is now available for suggesting that SRLs participate to this improvement in survival. In Sweden, excess mortality of patients with acromegaly decreased over time with a SMR of 3.45 (2.87-4.02) between 1987 and 1995 and 1.86 (1.04-2.67) during the time period 2005-2013 (71). This could be explained by an increasing use of pituitary surgery, decline of hypopituitarism and new medical treatments including SRLs. Indeed, in a retrospective study, SMR of well-controlled patients under SRLs was not increased compared with that of the general population (72). This was confirmed in a recent metaanalysis by Bolfi et al. (73). Before 2008, the mortality in acromegaly was increased with a SMR of 1.76 (1.52-2.4), whereas after 2008, the mortality was not different from that of the general population (SMR 1.26; 1.03-1.54) (73). However, the SMR was different according to the treatment. Indeed, mortality remained significantly higher in patients treated by surgery and radiotherapy (SMR: 2.11, 1.54-2.91). In studies where medical treatment with SRLs was used, the mortality was significantly lower than in the general population (SMR: 0.55; 0.37-0.82) contrary to studies where this therapy was not used (SMR: 0.94; 0.77-1.84) (73). The mortality was not increased in patients with biochemical control, while it was higher in patients with active disease. Thus, it is tempting to link the attrition of excess mortality observed in the last decades with the increase in the proportion of patients biochemically controlled which is not related to a higher number or a better success rate of surgical procedures but more likely to the increased use of medical treatment and particularly of SRLs $(74,75)$. It must be underlined that similar data on effects of SRLs on mortality are not available for PEGV therapy, at least for the moment.

\section{SRLs tolerance, safety and usability}

SRLs have mild adverse effects, consisting mainly of transient gastrointestinal disorders (abdominal bloating, nausea, diarrhoea) $(76,77,78,79,80,81,82)$, and also gallstones in $10-20 \%$ of cases (83). Gallstone complications are rare, and guidelines for their monitoring have been much relaxed (84). Changes in glucose metabolism under first-generation SRLs may rarely be observed, including impaired glucose tolerance or even diabetes in patients who are overweight. In other cases, however, glucose tolerance improves following the reduction in insulin resistance due to lowering of GH concentrations. In a study including 90 treatment-naïve patients with acromegaly, glycaemic status (HbA1c and fasting plasma glucose) from baseline to the end of the study (48 weeks) was stable in most patients $(70 \%$, including $76 \%$ of patients without diabetes and $50 \%$ of patients with diabetes) (85). A recent meta-analysis of prospective interventional trials, showed that SRLs, without affecting fasting plasma glucose, induce a small increase in HbA1c by reducing insulin levels and increasing after-load glucose (86). Even if the consequences are minor in terms of fasting glucose and HbA1c levels, regular metabolic monitoring is nevertheless justified.

While PEGV is administered sub-cutaneously once daily to thrice weekly, the SRLs have the major advantage of monthly injection, intramuscularly for octreotide LAR or by deep subcutaneous injection for lanreotide Autogel ${ }^{\circledR}$. The latter may even be injected by the patient himself $(33,87)$. However this opportunity is rarely used as only $17 \%$ of patients treated by monthly SRLs received injections at home and only $10 \%$ of patients treated with lanreotide were self-injecting (88) because $62 \%$ of the survey population considered that going to general practitioner's office or clinic for the injection was convenient or very convenient and around $65 \%$ did not feel a loss of independence due to the treatment. Despite injection-related symptoms (such as pain, nodules, swelling, bruising, skin inflammation at injection site), $77 \%$ of patients were satisfied and $67 \%$ were confident with their treatment (88).

Lastly, first-generation SRLs have been used now for more than 30 years and no safety signals have 
emerged during that very long time of surveillance providing reassurance about the long term use of this therapeutic class.

\section{Second-generation SRLs: pasireotide}

Octreotide and lanreotide bind with high affinity to somatostatin receptor subtypes sst2 and 5 . As a significant proportion of somatotroph adenomas appear partially or totally resistant to octreotide or lanreotide, possibly owing to variable expression or a reduced density of receptor subtypes (89), it was logical to develop new, more potent somatostatin analogues able to bind with greater affinity to certain ssts. Pasireotide (Signifor ${ }^{\circledR}$ ) is a new somatostatin analogue that binds with high affinity to sst1, 2, 3 and 5 (90) and that potently inhibits GH and IGF1 in different animal models (91). According to published studies, pasireotide seems more effective than octreotide in terms of the GH/IGF-I levels achieved (92). It is now available in long acting preparation which is administered every 28 days at a dose of 40 to $60 \mathrm{mg}$. In a head-to head prospective, randomized, double-blind trial led in treatment naive patients, biochemical control was achieved by significantly more pasireotide patients than octreotide patients (31.3\% vs $19.2 \%$ and $35.8 \%$ vs $20.9 \%$ when including patients with IGF-1 below the lower normal limit); gastrointestinal adverse events occurred at a similar frequency, but glucose metabolism was more strongly altered on pasireotide $(57.3 \%$ vs $21.7 \%$ in the head-to head comparison study) (93). This drug may be particularly interesting in patients with partial resistance to first-generation SRLs such as octreotide or lanreotide. This has been studied in a large multicentre randomized trial performed in patients inadequately controlled with maximal doses of octreotide or lanreotide: $15 \%$ of patients in the pasireotide $40 \mathrm{mg}$ group and $20 \%$ of patients in the pasireotide $60 \mathrm{mg}$ group achieved biochemical control, compared with no patients in the active control group (who pursued their previous SRLs treatment) (94). The most common adverse events were hyperglycaemia (33\% under $40 \mathrm{mg}$ pasireotide and 31\% under $60 \mathrm{mg}$ pasireotide, vs $14 \%$ with active control), and diabetes ( $21 \%$ under $60 \mathrm{mg}$ and $26 \%$ under $40 \mathrm{mg}$ pasireotide vs $8 \%$ in active controls). Diarrhoea was also more frequent during pasireotide in this trial (94). While, until now, PEGV was recommended as second-line medical treatment after first generation SRLs if they failed to control GH/IGF-I levels, pasireotide may be considered nowadays as an alternative more convenient second-line treatment which may be tried before resorting to pegvisomant $(2,5)$.
Nonetheless its place as first-line medical therapy, rather than first-generation SRLs such as octreotide or lanreotide, remains to be determined.

\section{Cost-effectiveness favours SRLS}

Cost-effectiveness is an important parameter to consider given that medical therapy is generally prescribed after surgery failure and is administered for very long time. In a UK study analysing cost-effectiveness of medical treatment in patients with acromegaly, PEGV was compared to a standard care pharmacological (SCP) treatment (95). The SCP treatment was long-acting SRLs and not much cheaper drugs such as dopamine agonists. The total annual cost for the standard care was $£ 15409$ and for PEGV was $£ 30482$ (95). This was not so far similar to a recent study using register-linkage population in Sweden (96). During 2013, the annual cost for SRLs was $€ 13500$ per patient while it was $€ 27700$ per patient under PEGV (96). The results of a study analysing the cost of the Consensus Group's recommendations confirmed that monthly SRLs should be used as the initial drug of choice in patients requiring medical therapy for acromegaly (97). Indeed the high cost of PEGV and the results of this cost on the overall value suggest that PEGV should continue to be reserved for patients who fail to achieve biochemical remission after SRLs monotherapy, alone or after the addition of a DA, while results for the efficacy of PEGV are notable (97).

\section{Conclusion}

Even if in recent studies, the remission rate is lower than expected, SRLs are still effective for decreasing/ normalizing GH/IGF-I levels but also for inducing tumour shrinkage (or at least controlling the tumour growth on long term) and improving comorbidities and headache. Importantly this class of drugs has a remarkable safety profile as demonstrated by the very long experience acquired by more than 30 years of use. This has to be confirmed for the second-generation SRL pasireotide which seems more effective than first-generation SRLs and is also convenient with its monthly administration. In terms of economic parameters, the cost-effectiveness of first generation SRLs is better than PEGV. For all these reasons, SRLs remain the best choice in patients requiring medical therapy as has be recommended in the guidelines of the Consensus Group. 


\section{Section 3: Pegvisomant and not somatostatin receptor ligands (SRLs) is first-line medical therapy for acromegaly. TENTATIVE SYNTHESIS}

When should we ideally use one versus the other as first line to improve biochemical and clinical outcomes? Both SRLs and PEGV have advantages and disadvantages. There is no discussion about the use of SRLs as first-line drug in case of large tumour impinging the optic chiasm; the presence of comorbidities (not only cardiovascular but also arthropathy) could also be another argument for the use of SRLs with regard to the amount of available documented evidence concerning their effects on comorbidity; persistent headache and convenience (monthly vs daily injection), product availability and cost may also be important reasons for choosing SRLs as first-line therapy. Conversely, it is clear that PEGV therapy is effective in a higher proportion of patients and could be preferred as first-line medical treatment if IGF-1 levels are very high, if the tumour is at distance of optic chiasm, if patients have impaired glucose tolerance or diabetes and if they agree with daily (eventually twice or thrice weekly) injections. Moreover, PEGV is as effective as first-line monotherapy as when given as adjunctive monotherapy after surgery (98). It is also quite clear that long term treatment with PEGV is not associated with tumour growth which is reassuring for the use of this drug as first-line medical treatment. In some patients, the association of SRLs and PEGV could be necessary for both controlling IGF-1 level, tumour size, headache, comorbidities but also reducing PEGV dose and injection frequency. The first-line medical treatment should be individualized taking into account tumour size, particularly its proximity to optic chiasm, comorbidities, glucose tolerance, headache, convenience for the patient. One might also keep in mind that the better treatment for the patient will be the treatment that he will accept best in order to optimize compliance and improve quality of life.

\section{Declaration of interest}

A J $v \mathrm{~d} L$ is or was a consultant for Novartis Pharma and Pfizer Inc. and received speakers' fees and grants from Novartis Pharma, Ipsen Pharmaceuticals, Tiburio, Crinetics Inc. and Pfizer Inc. S J M received research and speakers fee and grants from Ipsen Pharmaceuticals, Novartis Pharma, and Pfizer Inc. and a consulting fee from Ipsen Pharmaceuticals and Pfizer Inc. Ph C has received unrestricted research and educational grants from Ipsen, Novartis, Novo-Nordisk, and Pfizer; he has served as an investigator (principal or coordinator) for clinical trials funded by Novartis, Pfizer, Ipsen, Italpharmaco, Antisense, and Prolor Biotech; he is an advisory board member for Ipsen, Novartis, Pfizer, and Tiburio; he gave lectures for Ipsen, Novartis, and Pfizer. All the fees and honoraria are paid to his institution. The other authors have nothing to declare.

\section{Funding}

This article did not receive any specific grant from any funding agency in the public, commercial or not-for-profit sector.

\section{References}

1 Colao A, Grasso LFS, Giustina A, Melmed S, Chanson P, Pereira AM \& Pivonello R. Acromegaly. Nature Reviews: Disease Primers 2019520. (https://doi.org/10.1038/s41572-019-0071-6)

2 Melmed S, Bronstein MD, Chanson P, Klibanski A, Casanueva FF, Wass JAH, Strasburger CJ, Luger A, Clemmons DR \& Giustina A. A Consensus Statement on acromegaly therapeutic outcomes. Nature Reviews: Endocrinology 201814 552-561. (https://doi.org/10.1038/ s41574-018-0058-5)

3 Giustina A, Barkan A, Casanueva FF, Cavagnini F, Frohman L, Ho K, Veldhuis J, Wass J, Von Werder K \& Melmed S. Criteria for cure of acromegaly: a consensus statement. Journal of Clinical Endocrinology and Metabolism 200085 526-529. (https://doi.org/10.1210/jcem.85.2.6363)

4 Melmed S, Colao A, Barkan A, Molitch M, Grossman AB, Kleinberg D, Clemmons D, Chanson P, Laws E, Schlechte J et al. Guidelines for acromegaly management: an update. Journal of Clinical Endocrinology and Metabolism 200994 1509-1517. (https://doi.org/10.1210/jc.20082421)

5 Leonart LP, Ferreira VL, Tonin FS, Fernandez-Llimos F \& Pontarolo R. Medical treatments for acromegaly: a systematic review and network meta-analysis. Value in Health 201821 874-880. (https://doi. org/10.1016/j.jval.2017.12.014)

6 Leonart LP, Tonin FS, Ferreira VL, Fernandez-Llimos F \& Pontarolo R. Effectiveness and safety of pegvisomant: a systematic review and meta-analysis of observational longitudinal studies. Endocrine 2019 63 18-26. (https://doi.org/10.1007/s12020-018-1729-7)

7 Trainer PJ, Drake WM, Katznelson L, Freda PU, Herman-Bonert V, van der Lely AJ, Dimaraki EV, Stewart PM, Friend KE, Vance ML et al. Treatment of acromegaly with the growth hormone-receptor antagonist pegvisomant. New England Journal of Medicine 2000342 1171-1177. (https://doi.org/10.1056/NEJM200004203421604)

8 van der Lely AJ, Hutson RK, Trainer PJ, Besser GM, Barkan AL, Katznelson L, Klibanski A, Herman-Bonert V, Melmed S, Vance ML et al. Long-term treatment of acromegaly with pegvisomant, a growth hormone receptor antagonist. Lancet 2001358 1754-1759. (https://doi.org/10.1016/s0140-6736(01)06844-1)

9 Trainer PJ. ACROSTUDY: the first 5 years. European Journal of Endocrinology 2009161 (Supplement 1) S19-S24. (https://doi. org/10.1530/EJE-09-0322)

10 van der Lely AJ, Biller BM, Brue T, Buchfelder M, Ghigo E, Gomez R, Hey-Hadavi J, Lundgren F, Rajicic N, Strasburger CJ et al. Long-term safety of pegvisomant in patients with acromegaly: comprehensive review of 1288 subjects in ACROSTUDY. Journal of Clinical Endocrinology and Metabolism 201297 1589-1597. (https://doi. org/10.1210/jc.2011-2508)

11 Schreiber I, Buchfelder M, Droste M, Forssmann K, Mann K, Saller B, Strasburger CJ \& German Pegvisomant Investigators. Treatment of acromegaly with the GH receptor antagonist pegvisomant in clinical practice: safety and efficacy evaluation from the German pegvisomant Observational Study. European Journal of Endocrinology 2007156 75-82. (https://doi.org/10.1530/eje.1.02312)

12 Neggers SJ, Franck SE, de Rooij FW, Dallenga AH, Poublon RM, Feelders RA, Janssen JA, Buchfelder M, Hofland LJ, Jorgensen JO et al. Long-term efficacy and safety of pegvisomant in combination with long-acting somatostatin analogs in acromegaly. Journal of Clinical Endocrinology and Metabolism 201499 3644-3652. (https://doi. org/10.1210/jc.2014-2032)

13 Ragonese M, Grottoli S, Maffei P, Alibrandi A, Ambrosio MR, Arnaldi G, Bianchi A, Puglisi S, Zatelli MC, De Marinis L et al. How to improve effectiveness of pegvisomant treatment in acromegalic 
patients. Journal of Endocrinological Investigation 201841 575-581. (https://doi.org/10.1007/s40618-017-0773-0)

14 van der Lely AJ, Jonsson P, Wilton P, Akerblad AC, Cara J \& Ghigo E. Treatment with high doses of pegvisomant in 56 patients with acromegaly: experience from ACROSTUDY. European Journal of Endocrinology 2016175 239-245. (https://doi.org/10.1530/EJE-16-0008)

15 Auriemma RS, Pivonello R, De Martino MC, Cudemo G, Grasso LF, Galdiero M, Perone Y \& Colao A. Treatment with GH receptor antagonist in acromegaly: effect on cardiac arrhythmias. European Journal of Endocrinology 2013168 15-22. (https://doi.org/10.1530/ EJE-12-0596)

16 De Martino MC, Auriemma RS, Brevetti G, Vitale G, Schiano V, Galdiero M, Grasso L, Lombardi G, Colao A \& Pivonello R. The treatment with growth hormone receptor antagonist in acromegaly: effect on vascular structure and function in patients resistant to somatostatin analogues. Journal of Endocrinological Investigation 2010 33 663-670. (https://doi.org/10.1007/BF03346667)

17 Kuhn E, Maione L, Bouchachi A, Roziere M, Salenave S, BraillyTabard S, Young J, Kamenicky P, Assayag P \& Chanson P. Long-term effects of pegvisomant on comorbidities in patients with acromegaly: a retrospective single-center study. European Journal of Endocrinology 2015173 693-702. (https://doi.org/10.1530/EJE-15-0500)

18 Buchfelder M, van der Lely AJ, Biller BMK, Webb SM, Brue T, Strasburger CJ, Ghigo E, Camacho-Hubner C, Pan K, Lavenberg J et al. Long-term treatment with pegvisomant: observations from 2090 acromegaly patients in ACROSTUDY. European Journal of Endocrinology 2018179 419-427. (https://doi.org/10.1530/EJE-18-0616)

19 Besser GM, Burman P \& Daly AF. Predictors and rates of treatmentresistant tumor growth in acromegaly. European Journal of Endocrinology 2005153 187-193. (https://doi.org/10.1530/eje.1.01968)

20 Daly AF, Tichomirowa MA, Petrossians P, Heliovaara E, JaffrainRea ML, Barlier A, Naves LA, Ebeling T, Karhu A, Raappana A et al. Clinical characteristics and therapeutic responses in patients with germ-line AIP mutations and pituitary adenomas: an international collaborative study. Journal of Clinical Endocrinology and Metabolism 201095 E373-E383. (https://doi.org/10.1210/jc.2009-2556)

21 Bevan JS. Clinical review: the antitumoral effects of somatostatin analog therapy in acromegaly. Journal of Clinical Endocrinology and Metabolism 200590 1856-1863. (https://doi.org/10.1210/jc.2004-1093)

22 Bianchi A, Valentini F, Iuorio R, Poggi M, Baldelli R, Passeri M, Giampietro A, Tartaglione L, Chiloiro S, Appetecchia M et al. Longterm treatment of somatostatin analog-refractory growth hormonesecreting pituitary tumors with pegvisomant alone or combined with long-acting somatostatin analogs: a retrospective analysis of clinical practice and outcomes. Journal of Experimental and Clinical Cancer Research 201332 40. (https://doi.org/10.1186/1756-9966-32-40)

23 Franck SE, Muhammad A, van der Lely AJ \& Neggers SJ. Combined treatment of somatostatin analogues with pegvisomant in acromegaly. Endocrine 201652 206-213. (https://doi.org/10.1007/ s12020-015-0810-8)

24 Neggers SJ, de Herder WW, Janssen JA, Feelders RA \& van der Lely AJ. Combined treatment for acromegaly with long-acting somatostatin analogs and pegvisomant: long-term safety for up to 4.5 years (median 2.2 years) of follow-up in 86 patients. European Journal of Endocrinology 2009160 529-533. (https://doi.org/10.1530/EJE-08-0843)

25 Neggers SJ, van Aken MO, Janssen JA, Feelders RA, de Herder WW \& van der Lely AJ. Long-term efficacy and safety of combined treatment of somatostatin analogs and pegvisomant in acromegaly. Journal of Clinical Endocrinology and Metabolism 200792 4598-4601. (https:// doi.org/10.1210/jc.2007-1234)

26 Bonert VS, Kennedy L, Petersenn S, Barkan A, Carmichael J \& Melmed S. Lipodystrophy in patients with acromegaly receiving pegvisomant. Journal of Clinical Endocrinology and Metabolism 200893 3515-3518. (https://doi.org/10.1210/jc.2008-0833)

27 Melmed S \& Fagin JA. Acromegaly update - etiology, diagnosis and management. Western Journal of Medicine 1987146 328-336.
28 Melmed S, Vance ML, Barkan AL, Bengtsson BA, Kleinberg D, Klibanski A \& Trainer PJ. Current status and future opportunities for controlling acromegaly. Pituitary 20025 185-196. (https://doi. org/10.1023/a:1023369317275)

29 Muhammad A, Coopmans EC, Delhanty PJD, Dallenga AHG, Haitsma IK, Janssen JAMJL, van der Lely AJ \& Neggers SJCMM. Efficacy and safety of switching to pasireotide in acromegaly patients controlled with pegvisomant and somatostatin analogues: PAPE extension study. European Journal of Endocrinology 2018179 269-277. (https://doi.org/10.1530/EJE-18-0353)

30 Lamberts SWJ \& Hofland LJ. ANNIVERSARY REVIEW: Octreotide, 40 years later. European Journal of Endocrinology 2019181 R173-R183. (https://doi.org/10.1530/EJE-19-0074)

31 Lamberts SW, van der Lely AJ, de Herder WW \& Hofland LJ. Octreotide. New England Journal of Medicine 1996334 246-254. (https://doi.org/10.1056/NEJM199601253340408)

32 Chanson P. Medical treatment of acromegaly with dopamine agonists or somatostatin analogs. Neuroendocrinology 2016103 50-58. (https://doi.org/10.1159/000377704)

33 Bevan JS, Newell-Price J, Wass JA, Atkin SL, Bouloux PM, Chapman J, Davis JR, Howlett TA, Randeva HS, Stewart PM et al. Home administration of lanreotide Autogel by patients with acromegaly, or their partners, is safe and effective. Clinical Endocrinology 200868 343-349. (https://doi.org/10.1111/j.1365-2265.2007.03044.x)

34 Carmichael JD, Bonert VS, Nuno M, Ly D \& Melmed S. Acromegaly clinical trial methodology impact on reported biochemical efficacy rates of somatostatin receptor ligand treatments: a meta-analysis. Journal of Clinical Endocrinology and Metabolism 201499 1825-1833. (https://doi.org/10.1210/jc.2013-3757)

35 Abu Dabrh AM, Mohammed K, Asi N, Farah WH, Wang Z, Farah MH, Prokop LJ, Katznelson L \& Murad MH. Surgical interventions and medical treatments in treatment-naive patients with acromegaly: systematic review and meta-analysis. Journal of Clinical Endocrinology and Metabolism 201499 4003-4014. (https://doi.org/10.1210/ jc.2014-2900)

36 Ayuk J, Stewart SE, Stewart PM \& Sheppard MC. Long-term safety and efficacy of depot long-acting somatostatin analogs for the treatment of acromegaly. Journal of Clinical Endocrinology and Metabolism 2002 87 4142-4146. (https://doi.org/10.1210/jc.2001-011913)

37 Cozzi R, Attanasio R, Montini M, Pagani G, Lasio G, Lodrini S, Barausse M, Albizzi M, Dallabonzana D \& Pedroncelli AM. Four-year treatment with octreotide-long-acting repeatable in 110 acromegalic patients: predictive value of short-term results? Journal of Clinical Endocrinology and Metabolism 200388 3090-3098. (https://doi. org/10.1210/jc.2003-030110)

38 Maiza JC, Vezzosi D, Matta M, Donadille F, Loubes-Lacroix F, Cournot M, Bennet A \& Caron P. Long-term (up to 18 years) effects on GH/IGF-1 hypersecretion and tumour size of primary somatostatin analogue (SSTa) therapy in patients with GH-secreting pituitary adenoma responsive to SSTa. Clinical Endocrinology 200767 282-289. (https://doi.org/10.1111/j.1365-2265.2007.02878.x)

39 Ramirez C, Vargas G, Gonzalez B, Grossman A, Rabago J, Sosa E, Espinosa-de-Los-Monteros AL \& Mercado M. Discontinuation of octreotide LAR after long term, successful treatment of patients with acromegaly: is it worth trying? European Journal of Endocrinology 2012 166 21-26. (https://doi.org/10.1530/EJE-11-0738)

40 Ronchi CL, Rizzo E, Lania AG, Pivonello R, Grottoli S, Colao A, Ghigo E, Spada A, Arosio M \& Beck-Peccoz P. Preliminary data on biochemical remission of acromegaly after somatostatin analogs withdrawal. European Journal of Endocrinology 2008158 19-25. (https://doi.org/10.1530/EJE-07-0488)

41 Melmed S, Sternberg R, Cook D, Klibanski A, Chanson P, Bonert V, Vance ML, Rhew D, Kleinberg D \& Barkan A. A critical analysis of pituitary tumor shrinkage during primary medical therapy in acromegaly. Journal of Clinical Endocrinology and Metabolism 200590 4405-4410. (https://doi.org/10.1210/jc.2004-2466) 
42 Giustina A, Mazziotti G, Torri V, Spinello M, Floriani I \& Melmed S Meta-analysis on the effects of octreotide on tumor mass in acromegaly. PLoS ONE 20127 e36411. (https://doi.org/10.1371/ journal.pone.0036411)

43 Colao A, Ferone D, Marzullo P, Cappabianca P, Cirillo S, Boerlin V, Lancranjan I \& Lombardi G. Long-term effects of depot long-acting somatostatin analog octreotide on hormone levels and tumor mass in acromegaly. Journal of Clinical Endocrinology and Metabolism 2001 86 2779-2786. (https://doi.org/10.1210/jcem.86.6.7556)

44 Colao A, Auriemma RS \& Pivonello R. The effects of somatostatin analogue therapy on pituitary tumor volume in patients with acromegaly. Pituitary 201619 210-221. (https://doi.org/10.1007/ s11102-015-0677-y)

45 Caron PJ, Bevan JS, Petersenn S, Flanagan D, Tabarin A, Prevost G, Maisonobe P, Clermont A \& PRIMARYS Investigators. Tumor shrinkage with lanreotide Autogel $120 \mathrm{mg}$ as primary therapy in acromegaly: results of a prospective multicenter clinical trial. Journal of Clinical Endocrinology and Metabolism 201499 1282-1290. (https:// doi.org/10.1210/jc.2013-3318)

46 Chanson P, Timsit J, Masquet C, Warnet A, Guillausseau PJ, Birman P, Harris AG \& Lubetzki J. Cardiovascular effects of the somatostatin analog octreotide in acromegaly. Annals of Internal Medicine 1990113 921-925. (https://doi.org/10.7326/0003-4819-113-12-921)

47 Colao A, Cuocolo A, Marzullo P, Nicolai E, Ferone D, Della Morte AM, Petretta M, Salvatore M \& Lombardi G. Impact of patient's age and disease duration on cardiac performance in acromegaly: a radionuclide angiography study. Journal of Clinical Endocrinology and Metabolism 199984 1518-1523. (https://doi. org/10.1210/jcem.84.5.5674)

48 Colao A, Marzullo P, Cuocolo A, Spinelli L, Pivonello R, Bonaduce D, Salvatore M \& Lombardi G. Reversal of acromegalic cardiomyopathy in young but not in middle-aged patients after 12 months of treatment with the depot long-acting somatostatin analogue octreotide. Clinical Endocrinology 200358 169-176. (https://doi. org/10.1046/j.1365-2265.2003.01689.x)

49 Maison P, Tropeano AI, Macquin-Mavier I, Giustina A \& Chanson P. Impact of somatostatin analogs on the heart in acromegaly: a metaanalysis. Journal of Clinical Endocrinology and Metabolism 200792 1743-1747. (https://doi.org/10.1210/jc.2006-2547)

50 Bogazzi F, Lombardi M, Strata E, Aquaro G, Lombardi M, Urbani C, Di Bello V, Cosci C, Sardella C, Talini E et al. Effects of somatostatin analogues on acromegalic cardiomyopathy: results from a prospective study using cardiac magnetic resonance. Journal of Endocrinological Investigation 201033 103-108. (https://doi. org/10.1007/BF03346562)

51 Colao A. Improvement of cardiac parameters in patients with acromegaly treated with medical therapies. Pituitary 201215 50-58. (https://doi.org/10.1007/s11102-011-0318-z)

52 Annamalai AK, Webb A, Kandasamy N, Elkhawad M, Moir S, Khan F, Maki-Petaja K, Gayton EL, Strey CH, O'Toole S et al. A comprehensive study of clinical, biochemical, radiological, vascular, cardiac, and sleep parameters in an unselected cohort of patients with acromegaly undergoing presurgical somatostatin receptor ligand therapy. Journal of Clinical Endocrinology and Metabolism 201398 1040-1050. (https:// doi.org/10.1210/jc.2012-3072)

53 Sardella C, Cappellani D, Urbani C, Manetti L, Marconcini G, Tomisti L, Lupi I, Rossi G, Scattina I, Lombardi M et al. Disease activity and lifestyle influence comorbidities and cardiovascular events in patients with acromegaly. European Journal of Endocrinology 2016175 443-453. (https://doi.org/10.1530/EJE-16-0562)

54 Gadelha MR, Kasuki L, Lim DST \& Fleseriu M. Systemic complications of acromegaly and the impact of the current treatment landscape: an update. Endocrine Reviews 201940 268-332. (https:// doi.org/10.1210/er.2018-00115)

55 Ip MSM, Tan KCB, Peh WCG \& Lam KSL. Effect of Sandostatin ${ }^{\circledR}$ $\mathrm{LAR}^{\circledR}$ on sleep apneoa in acromegaly: correlation with computerized tomographic cephalometry and hormonal activity. Clinical Endocrinology 200155 477-483. (https://doi.org/10.1046/j.13652265.2001.01358.x)

56 Herrmann BL, Wessendorf TE, Ajaj W, Kahlke S, Teschler H \& Mann K. Effects of octreotide on sleep apnoea and tongue volume (magnetic resonance imaging) in patients with acromegaly. European Journal of Endocrinology 2004151 309-315. (https://doi.org/10.1530/ eje.0.1510309)

57 Attal P \& Chanson P. Endocrine aspects of obstructive sleep apnea. Journal of Clinical Endocrinology and Metabolism 201095 483-495. (https://doi.org/10.1210/jc.2009-1912)

58 Chemla D, Attal P, Maione L, Veyer AS, Mroue G, Baud D, Salenave S, Kamenicky P, Bobin S \& Chanson P. Impact of successful treatment of acromegaly on overnight heart rate variability and sleep apnea. Journal of Clinical Endocrinology and Metabolism 201499 2925-2931. (https://doi.org/10.1210/jc.2013-4288)

59 Wolters TLC, Roerink SHPP, Drenthen LCA, van HarenWillems JHGM, Wagenmakers MAEM, Smit JWA, Hermus ARMM $\&$ Netea-Maier RT. The course of obstructive sleep apnea syndrome in patients with acromegaly during treatment. Journal of Clinical Endocrinology and Metabolism 2020105 dgz050. (https://doi. org/10.1210/clinem/dgz050)

60 Colao A, Marzullo P, Vallone G, Marino V, Annecchino M, Ferone D, De Brasi D, Scarpa R, Oriente P \& Lombardi G. Reversibility of joint thickening in acromegalic patients: an ultrasonography study. Journal of Clinical Endocrinology and Metabolism 199883 2121-2125. (https:// doi.org/10.1210/jcem.83.6.4865)

61 Colao A, Cannavo S, Marzullo P, Pivonello R, Squadrito S, Vallone G, Almoto B, Bichisao E, Trimarchi F \& Lombardi G. Twelve months of treatment with octreotide-LAR reduces joint thickness in acromegaly. European Journal of Endocrinology 2003148 31-38. (https://doi. org/10.1530/eje.0.1480031)

62 Colao A, Auriemma RS, Pivonello R, Galdiero M \& Lombardi G. Medical consequences of acromegaly: what are the effects of biochemical control? Reviews in Endocrine and Metabolic Disorders 20089 21-31. (https://doi.org/10.1007/s11154-007-9062-0)

63 Levy MJ, Matharu MS, Meeran K, Powell M \& Goadsby PJ. The clinical characteristics of headache in patients with pituitary tumours. Brain 2005128 1921-1930. (https://doi.org/10.1093/brain/awh525)

64 Kreitschmann-Andermahr I, Siegel S, Weber Carneiro R, Maubach JM, Harbeck B \& Brabant G. Headache and pituitary disease: a systematic review. Clinical Endocrinology 201379 760-769. (https://doi.org/10.1111/cen.12314)

65 Otsuka F, Kageyama J, Ogura T \& Makino H. Cluster headache dependent upon octreotide injection. Headache 199838629. (https://doi.org/10.1046/j.1526-4610.1998.00629.x)

66 May A, Lederbogen S \& Diener HC. Octreotide dependency and headache: a case report. Cephalalgia 199414 303-304. (https://doi. org/10.1046/j.1468-2982.1994.1404303.x)

67 Popovic V, Paunovic VR, Micic D, Nesovic M, Kendereski A, Djordjevic P, Manojlovic D \& Micic J. The analgesic effect and development of dependency to somatostatin analogue (octreotide) in headache associated with acromegaly. Hormone and Metabolic Research 198820 250-251. (https://doi.org/10.1055/s-2007-1010806)

68 Schreiber I, Buchfelder M, Droste M, Forssmann K, Mann K, Saller B, Strasburger CJ \& German Pegvisomant Investigators. Treatment of acromegaly with the GH receptor antagonist pegvisomant in clinical practice: safety and efficacy evaluation from the German pegvisomant Observational Study. European Journal of Endocrinology 2007156 75-82. (https://doi.org/10.1530/eje.1.02312)

69 Dekkers OM, Biermasz NR, Pereira AM, Romijn JA \& Vandenbroucke JP. Mortality in acromegaly: a metaanalysis. Journal of Clinical Endocrinology and Metabolism 200893 61-67. (https://doi. org/10.1210/jc.2007-1191)

70 Sherlock M, Ayuk J, Tomlinson JW, Toogood AA, Aragon-Alonso A, Sheppard MC, Bates AS \& Stewart PM. Mortality in patients with 
pituitary disease. Endocrine Reviews 201031 301-342. (https://doi. org/10.1210/er.2009-0033)

71 Esposito D, Ragnarsson O, Granfeldt D, Marlow T, Johannsson G \& Olsson DS. Decreasing mortality and changes in treatment patterns in patients with acromegaly from a nationwide study. European Journal of Endocrinology 2018178 459-469. (https://doi.org/10.1530/EJE-18-0015)

72 Postma MR, Wolters TLC, van den Berg G, van Herwaarden AE, Muller Kobold AC, Sluiter WJ, Wagenmakers MA, van den Bergh ACM, Wolffenbuttel BHR, Hermus ARMM et al. Postoperative use of somatostatin analogs and mortality in patients with acromegaly. European Journal of Endocrinology 2019180 1-9. (https:// doi.org/10.1530/EJE-18-0166)

73 Bolfi F, Neves AF, Boguszewski CL \& Nunes-Nogueira VS. Mortality in acromegaly decreased in the last decade: a systematic review and meta-analysis. European Journal of Endocrinology 2018179 59-71. (https://doi.org/10.1530/EJE-18-0255)

74 Maione L, Brue T, Beckers A, Delemer B, Petrossians P, Borson-Chazot F, Chabre $\mathrm{O}$, Francois $\mathrm{P}$, Bertherat J, Cortet-Rudelli $\mathrm{C}$ et al. Changes in the management and comorbidities of acromegaly over three decades: the French Acromegaly Registry. European Journal of Endocrinology 2017176 645-655. (https://doi.org/10.1530/EJE-16-1064)

75 Maione L \& Chanson P. National acromegaly registries. Best Practice and Research: Clinical Endocrinology and Metabolism 201933101264. (https://doi.org/10.1016/j.beem.2019.02.001)

76 Gillis JC, Noble S \& Goa KL. Octreotide long-acting release (LAR). A review of its pharmacological properties and therapeutic use in the management of acromegaly. Drugs 199753 681-699. (https://doi. org/10.2165/00003495-199753040-00009)

77 McKeage K, Cheer S \& Wagstaff AJ. Octreotide long-acting release (LAR): a review of its use in the management of acromegaly. Drugs 2003 63 2473-2499. (https://doi.org/10.2165/00003495-200363220-00014)

78 Yang LP \& Keating GM. Octreotide long-acting release (LAR): a review of its use in the management of acromegaly. Drugs $2010 \mathbf{7 0}$ 1745-1769. (https://doi.org/10.2165/11204510-000000000-00000)

79 Molitch ME. Lanreotide Autogel in the management of acromegaly. Drugs 200868 724. (https://doi.org/10.2165/00003495-20086805000014)

80 Croxtall JD \& Scott LJ. Lanreotide Autogel: a review of its use in the management of acromegaly. Drugs 200868 711-723. (https://doi. org/10.2165/00003495-200868050-00013)

81 Burness CB, Dhillon S \& Keam SJ. Lanreotide autogel((R)): a review of its use in the treatment of patients with acromegaly. Drugs $2014 \mathbf{7 4}$ 1673-1691. (https://doi.org/10.1007/s40265-014-0283-8)

82 Grasso LF, Auriemma RS, Pivonello R \& Colao A. Adverse events associated with somatostatin analogs in acromegaly. Expert Opinion on Drug Safety 201514 1213-1226. (https://doi.org/10.1517/1474033 8.2015.1059817)

83 Attanasio R, Mainolfi A, Grimaldi F, Cozzi R, Montini M, Carzaniga C, Grottoli S, Cortesi L, Albizzi M, Testa RM et al. Somatostatin analogs and gallstones: a retrospective survey on a large series of acromegalic patients. Journal of Endocrinological Investigation 200831 704-710. (https://doi.org/10.1007/BF03346419)

84 Katznelson L, Laws Jr ER, Melmed S, Molitch ME, Murad MH, Utz A, Wass JA \& Endocrine Society. Acromegaly: an Endocrine Society Clinical Practice guideline. Journal of Clinical Endocrinology and Metabolism 201499 3933-3951. (https://doi.org/10.1210/jc.2014-2700)

85 Caron PJ, Petersenn S, Houchard A, Sert C, Bevan JS \& PRIMARYS Study Group. Glucose and lipid levels with lanreotide autogel 120 $\mathrm{mg}$ in treatment-naive patients with acromegaly: data from the PRIMARYS study. Clinical Endocrinology 201786 541-551. (https:// doi.org/10.1111/cen.13285)

86 Cozzolino A, Feola T, Simonelli I, Puliani G, Pozza C, Giannetta E, Gianfrilli D, Pasqualetti P, Lenzi A \& Isidori AM. Somatostatin analogs and glucose metabolism in acromegaly: a meta-analysis of prospective interventional studies. Journal of Clinical Endocrinology and Metabolism 2018. (https://doi.org/10.1210/jc.2017-02566)

87 Salvatori R, Woodmansee WW, Molitch M, Gordon MB \& Lomax KG. Lanreotide extended-release aqueous-gel formulation, injected by patient, partner or healthcare provider in patients with acromegaly in the United States: 1-year data from the soda registry. Pituitary 2014 17 13-21. (https://doi.org/10.1007/s11102-012-0460-2)

88 Strasburger CJ, Karavitaki N, Stormann S, Trainer PJ, KreitschmannAndermahr I, Droste M, Korbonits M, Feldmann B, Zopf K, Sanderson VF et al. Patient-reported outcomes of parenteral somatostatin analogue injections in 195 patients with acromegaly. European Journal of Endocrinology 2016174 355-362. (https://doi. org/10.1530/EJE-15-1042)

89 Hofland LJ \& Lamberts SW. The pathophysiological consequences of somatostatin receptor internalization and resistance. Endocrine Reviews 200324 28-47. (https://doi.org/10.1210/er.2000-0001)

90 Bruns C, Lewis I, Briner U, Meno-Tetang G \& Weckbecker G. SOM230: a novel somatostatin peptidomimetic with broad somatotropin release inhibiting factor (SRIF) receptor binding and a unique antisecretory profile. European Journal of Endocrinology 2002 146 707-716. (https://doi.org/10.1530/eje.0.1460707)

91 Hofland LJ, van der Hoek J, van Koetsveld PM, de Herder WW, Waaijers M, Sprij-Mooij D, Bruns C, Weckbecker G, Feelders R, van der Lely AJ et al. The novel somatostatin analog SOM230 is a potent inhibitor of hormone release by growth hormone- and prolactinsecreting pituitary adenomas in vitro. Journal of Clinical Endocrinology and Metabolism 200489 1577-1585. (https://doi.org/10.1210/ jc.2003-031344)

92 Petersenn S, Schopohl J, Barkan A, Mohideen P, Colao A, Abs R, Buchelt A, Ho YY, Hu K, Farrall AJ et al. Pasireotide (SOM230) demonstrates efficacy and safety in patients with acromegaly: a randomized, multicenter, phase II trial. Journal of Clinical Endocrinology and Metabolism 201095 2781-2789. (https://doi. org/10.1210/jc.2009-2272)

93 Colao A, Bronstein MD, Freda P, Gu F, Shen CC, Gadelha M, Fleseriu M, van der Lely AJ, Farrall AJ, Hermosillo Resendiz K et al. Pasireotide versus octreotide in acromegaly: a head-to-head superiority study. Journal of Clinical Endocrinology and Metabolism 201499 791-799. (https://doi.org/10.1210/jc.2013-2480)

94 Gadelha MR, Bronstein MD, Brue T, Coculescu M, Fleseriu M, Guitelman M, Pronin V, Raverot G, Shimon I, Lievre KK et al. Pasireotide versus continued treatment with octreotide or lanreotide in patients with inadequately controlled acromegaly (PAOLA): a randomised, phase 3 trial. Lancet: Diabetes and Endocrinology 20142 875-884. (https://doi.org/10.1016/S22138587(14)70169-X)

95 Moore DJ, Adi Y, Connock MJ \& Bayliss S. Clinical effectiveness and cost-effectiveness of pegvisomant for the treatment of acromegaly: a systematic review and economic evaluation. BMC Endocrine Disorders 20099 20. (https://doi.org/10.1186/1472-6823-9-20)

96 Lesen E, Granfeldt D, Houchard A, Dinet J, Berthon A, Olsson DS, Bjorholt I \& Johannsson G. Comorbidities, treatment patterns and cost-of-illness of acromegaly in Sweden: a register-linkage population-based study. European Journal of Endocrinology 2017176 203-212. (https://doi.org/10.1530/EJE-16-0623)

97 Kimmell KT, Weil RJ \& Marko NF. Multi-modal management of acromegaly: a value perspective. Pituitary 201518 658-665. (https:// doi.org/10.1007/s11102-014-0626-1)

98 Tritos NA, Chanson P, Jimenez C, King D, Jonsson PJ, Klibanski A \& Biller BM. Effectiveness of first-line pegvisomant monotherapy in acromegaly: an ACROSTUDY analysis. European Journal of Endocrinology 2017176 213-220. (https://doi.org/10.1530/EJE-16-0697)

Received 8 December 2019

Revised version received 21 February 2020

Accepted 1 April 2020 